Anatomical Science (2018) Volume 1

doi:10.24294/as.v1i3.452

\title{
Case Report Of Digital Necrosis Due To Radial Artery Injury And An Association With The Arterial Anatomy Of The Hand
}

\section{Luciano Zogbi}

Universidade Federal do Rio Grande (FURG)

\section{ABSTRACT}

Radial artery puncture, an invasive procedure, is frequently used in critically-ill patients. Although considered safe, severe and rare complications such as finger necrosis can occur. Here we report a case of finger necrosis and discuss its relationship with the anatomy of hand arteries

Keywords: Anatomy; Radial Artery; Thrombosis

\section{Introduction}

Radial artery puncture, an invasive procedure, is frequently used in critically-ill patients. Although considered safe, severe and rare complications such as finger necrosis can occur ${ }^{1-4}$. Here we report a case of finger necrosis and discuss its relationship with the anatomy of hand arteries.

\section{Case report}

A 34-year-old male patient developed community-acquired pneumonia, refractory to amoxicillin, 3 days prior to admission. The pneumonia manifested as fatigue, general malaise, fever and progressive dyspnea, evolving to acute respiratory failure. He was admitted to an intensive care unit (ICU). The patient was sedated intubated and underwent positive pressure ventilation. His antibiotic therapy included Imipenem and Vancomycin. He had a good clinical and laboratory response, without the need for vasopressors. On the $3^{\text {rd }}$ day of ICU stay, however, the patient developed ischemia of the $1^{\text {st }}$ and $2^{\text {nd }}$ finger due to an embolism caused by the invasive pressure measurement catheter in the radial artery. The ischemia progressed to necrosis of these extremities even after the immediate removal of the catheter (Figures 1 and 2).



Figure 1; Anterior view. 


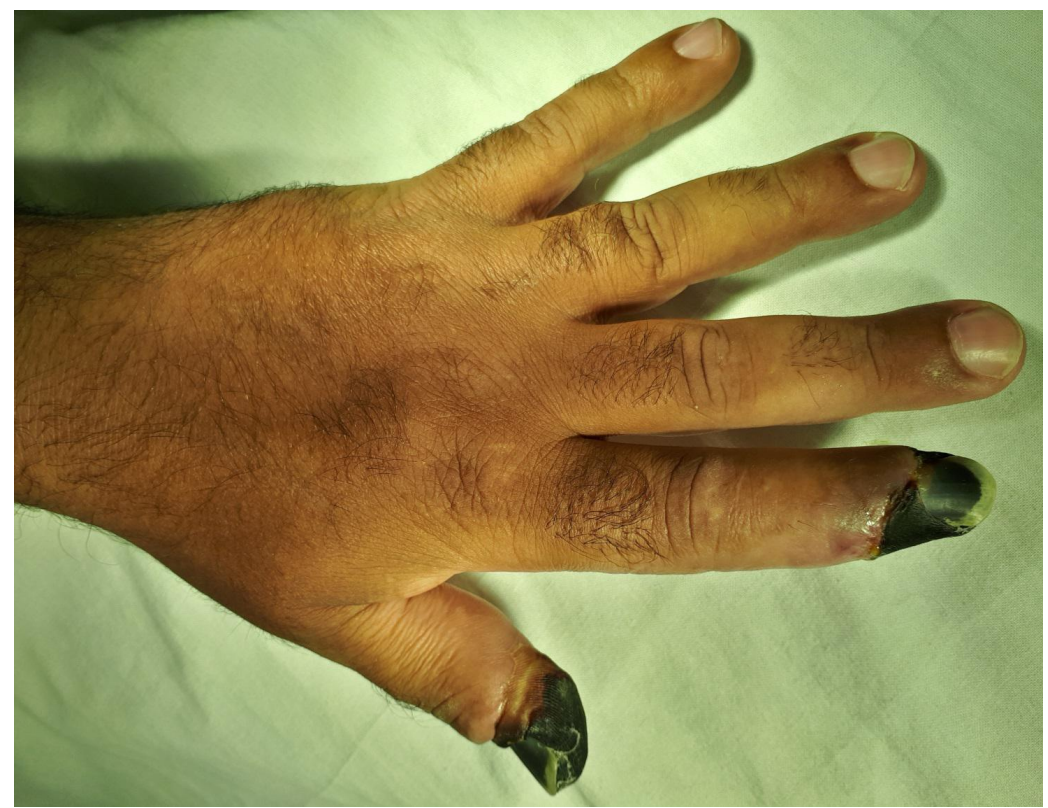

Figure 2; Posterior view.

Throughout his hospitalization, the remaining areas of his extremities remained warm and acyanotic. The patient had previous history of smoking and alcoholism, with no other comorbidities. The total ICU stay was 10 days, and the patient underwent amputation of the necrotic extremities after discharge, with no other complications.

\section{Discussion}

The radial artery forms a deep and a superficial arch with the ulnar artery, from which emerge the digital arteries to supply the fingers. The radial side supplies mainly the thumb and forefinger, especially from the deep arch, while the ulnar side supplies predominantly the remaining digits. Therefore, in this case, the lesion in the radial artery promoted formation of an embolism leading to infarction in the first two fingers. Because of the collateral ulnar branches, the remaining fingers were preserved during this thromboembolic event (Figure 3) ${ }^{[1,5]}$.

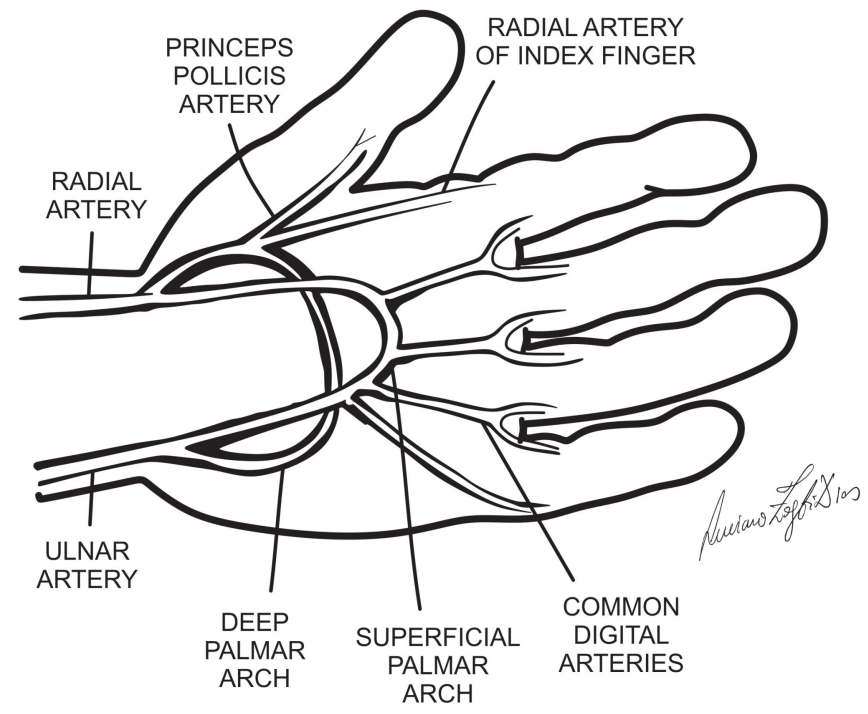

Figure 3; Schematic drawing of the hand arteries and its anatomical relationships. 
Hand ischemia is caused usually either by digital embolization of a radial artery thrombus or by in situ thrombosis of collateral vessels because of severe vasospasm. The latter usually occurs in the setting of normal radial, ulnar, and superficial palmar arteries. Fortunately, permanent ischemic damage is a very rare adverse event, with rates of $0.09 \% \%^{[1-4]}$.

This case highlights that care should be taken with routine invasive procedures, and one should be aware of the relevant anatomy ${ }^{[5-7]}$.

\section{References}

1. Scheer B, Perel A, Pfeiffer UJ. Clinical review: complications and risk factors of peripheral arterial catheters used for haemodynamic monitoring in anaesthesia and intensive care medicine. Crit Care 2002;6:199-204.

2. Singh K, Abunassar J, So DY. Digital gangrene following transradial coronary angiogram. J Am Coll Cardiol Intv 2016;9:21-2.

3. Kang JS, Lee TR, Cha WC, Shin TG, Sim MS, Jo IJ, Song KJ, Rhee JE, Jeong YK. Finger necrosis after accidental radial artery puncture. Clin Exp Emerg Med 2014;1(2):130-133.

4. Lin TL, Huang F, Chen CC, Shih HS, Hsieh CH. Multiple digital gangrene after a radial artery penetrating injury: a case report. Ann Vasc Surg 2007; 21(3):384-7.

5. Miletin J, Sukop A, Baca V, Kachlik D. Arterial supply of the thumb: systemic review. Clinical Anatomy, 2017; 30(7): 963-73.

6. Pancholy S, Coppola J, Patel T, Roke-Thomas M. Prevention of Radial Artery Occlusion-Patent Hemostasis Evaluation Trial (PROPHET study): a randomized comparison of traditional versus patency documented hemostasis after transradial catheterization. Cathet Cardiovasc Interv 2008;72: $335-40$.

7. Valgimigli M, Gagnor A, Calabro P, et al. Radial versus femoral access in patients with acute coronary syndromes undergoing invasive management: a randomised multicentre trial. Lancet 2015;385:2465-76. 